\title{
Drosophila as a Model to Study Mitochondrial Dysfunction in Parkinson's Disease
}

\author{
Ming Guo \\ Department of Neurology, Department of Molecular and Medical Pharmacology, Brain Research Institute, \\ David Geffen School of Medicine, Los Angeles, California 90095 \\ Correspondence: mingfly@ucla.edu
}

\begin{abstract}
Identification of single gene mutations that lead to inherited forms of Parkinson's disease (PD) has provided strong impetus for the use of animal models to study normal functions of these "PD genes" and the cellular defects that occur in the presence of pathogenic PD mutations. Drosophila has emerged as an effective model in PD-related gene studies. Important insights into the cellular basis of PD pathogenesis include the demonstration that two PD genes, PINK1 and parkin, function in a common pathway, with PINK1 positively regulating parkin, to control mitochondrial integrity and maintenance. This is accomplished through regulation of mitochondrial fission/fusion dynamics. Subsequent observations in both fly and mammalian systems showed that these proteins are important for sensing mitochondrial damage and recruiting damaged mitochondria to the quality-control machinery for subsequent removal. Here, I begin by reviewing the opportunities and challenges to understanding PD pathogenesis and developing new therapies. I then review the unique tools and technologies available in Drosophila for studying PD genes. Subsequently, I review lessons that we have learned from studies in Drosophila, emphasizing the PINK1/parkin pathway, as well as studies of DJ-1 and Omi/HtrA2, two additional genes associated with PD implicated in regulation of mitochondrial function. I end by discussing how Drosophila can be used to further probe the functions of PINK1 and parkin, and the regulation of mitochondrial quality more generally. In additional to PD, defects in mitochondrial function are associated with normal aging and with many diseases of aging. Thus, insights gained from the studies of mitochondrial dynamics and quality control in Drosophila are likely to be of general significance.
\end{abstract}

Darkinson's disease (PD) is the second most common neurodegenerative disorder, with a prevalence second only to that of Alzheimer's disease. There is no cure or treatment that can halt disease progression. A primary pathological hallmark of the disease is degeneration of multiple neuronal types including, most notably, dopaminergic neurons in the substantia nigra of the midbrain (Dauer and Przedborski 2003; Shulman et al. 2011). However, pathology of many non-dopaminergic neurons including olfactory and brain stem neurons predates that of DA neurons (Braak et al. 2003). Patients with PD present with characteristic "motor symptoms," such as resting tremor, slowness of movement, rigidity, postural instability, and gait difficulty.

Editor: Serge Przedborski

Additional Perspectives on Parkinson's Disease available at www.perspectivesinmedicine.org

Copyright (C) 2012 Cold Spring Harbor Laboratory Press; all rights reserved; doi: 10.1101/cshperspect.a009944

Cite this article as Cold Spring Harb Perspect Med 2012;2:a009944 
M. Guo

Although the mainstay of current medical treatment for PD is dopamine replacement, this is not very satisfying. First, the dopamine replacement only alleviates some of the motor symptoms (does not help gait problems), becomes less effective over time, and is often associated with intolerable side effects. Second, PD patients also present with a combination of non-motor symptoms (Simuni and Sethi 2008) including dementia, which occurs in more than one-third of patients; psychiatric symptoms such as depression, anxiety, and obsession; autonomic dysfunction (involving cardiac and digestive systems); sleep disruption; skin lesions; and musculoskeletal abnormalities (Meissner et al. $2011 b)$. Some of these non-motor symptoms may be more debilitating than the motor impairment, but they do not usually respond to dopamine replacement. Third, because of the progressive, debilitating nature of the disease, there is an urgent need to develop disease-modifying therapies that can prevent progression of the illness and perhaps even revert some of the pathology. In summary, PD is a multisystem disease affecting more than DA neurons. Therefore, although therapies targeted to dopaminergic neurons or their targets (such as dopamine replacement, cell transplantation, deep brain stimulation) can provide some therapeutic benefit to patients, particularly with respect to the motor symptoms, we still need to develop therapies that target the underlying cellular defects so as to treat both motor and non-motor symptoms and to prevent disease progression in the first place. A prerequisite for developing these new therapies is that we understand the pathogenesis of PD at the cellular and molecular level in tissues beyond dopaminergic neurons.

\section{IDENTIFICATION OF PD GENES PROVIDES STRONG IMPETUS FOR STUDIES USING ANIMAL MODELS}

Vertebrate models have been used in the PD field for many years. Once believed to be solely an environmental disease, much early work focused on toxin models of PD to study disease pathogenesis and develop therapies. Following the landmark discovery that exposure to the mi- tochondrial toxin 1-methyl-4-phenyl-1,2,3,6tetrahydropyridine (MPTP) leads to loss of dopaminergic neurons and motor-related PD-like symptoms in humans (Langston et al. 1983; Bove et al. 2005), rodent and primate models were developed that used chemical depletion of dopamine using 6-hydroxy-dopamine, or feeding with mitochondrial toxins such as MPTP, rotenone, or paraquat (Bove et al. 2005). The results of these studies led to the important conclusion that dopaminergic neuronal degeneration results from oxidative stress and mitochondrial dysfunction (Abou-Sleiman et al. 2006).

Although the above toxin models show dopaminergic neuronal degeneration, new anti-PD drugs and neuroprotective agents that work well to alleviate symptoms in these animal models have largely failed to yield positive effects in human trials (Linazasoro 2004; Meissner et al. 2011b). These results suggest that the disease mechanisms underlying pharmacological models of PD may be different from those acting in the vast majority of sporadic PD patients.

The identification of genes that mediate familial PD has transformed our understanding of the genetic contribution to $\mathrm{PD}$ and is providing insight into the cellular mechanisms underlying PD pathogenesis (Hardy et al. 2009; Martin et al. 2011). Over the past 15 years, mutations in several genes have been definitively shown to mediate familial PD. Mutations in SNCA (encoding $\alpha$-synuclein to PARK1 [Polymeropoulos et al. 1997] and PARK4 [Singleton et al. 2003], Leucine-rich repeat kinase 2 (LRRK2)/Dardarin (PARK8) [Paisan-Ruiz et al. 2004; Zimprich et al. 2004]) were identified several years ago as being associated with autosomal-dominant forms of the disease. More recently, mutations in VPS35 (Vilarino-Guell et al. 2011; Zimprich et al. 2011) and EIF4G1 (Chartier-Harlin et al. 2011) have been reported to cause autosomaldominant forms of PD. Mutations in PARKIN (PARK2) (Kitada et al. 1998), DJ-1 (PARK7) (Bonifati et al. 2003), and PTEN-induced kinase 1 (PINK1, PARK6) (Valente et al. 2004) are associated with autosomal-recessive forms of $\mathrm{PD}$. Mutations in ATP13A2 (PARK9), which encodes a lysosomal ATPase, have also been found in an atypical, autosomal-recessive parkinsonism 
(Ramirez et al. 2006) with distinct clinical manifestations (Schneider et al. 2010). These singlegene, Mendelian forms represent $\sim 10 \%-15 \%$ of all PD cases. Some patients with familial forms of PD show clinical symptoms that are similar to those present in patients with sporadic cases. In addition, genome-wide association studies have provided evidence that polymorphic variants in some of the genes associated with familial PD contribute to sporadic PD (Satake et al. 2009; Simon-Sanchez et al. 2009). Thus, the distinction between sporadic and familial forms of PD has become increasingly blurred, and the knowledge gained from studies of genes associated with inherited forms of PD will likely provide insight into mechanisms underlying sporadic forms of the disease as well.

Although human genetic studies have allowed the identification of PD genes from patient-based studies, ethical and technical considerations constrain the utilization of human subjects as experimental systems. Human cellbased studies are limited by tissue availability and provide only limited information when studying processes at the tissue, organ, or wholeanimal levels. Postmortem studies are also limited by tissue availability and seldom allow identification of the initial pathological events during presymptomatic stages. Overall, it is difficult to determine the causality of mechanisms from human studies. Thus, animal models are indispensable tools for the analysis of PD genes.

Why do we need invertebrate models if vertebrate models can be easily generated? Vertebrate models include non-human primates, rodents (mice and rats), zebrafish, frogs, and chickens. Mouse models predominate, because of the large number of genetic technologies available and the long history of cell biology and analysis of behaviors in this organism. It might be assumed that mouse models are superior to invertebrate models, because mice are evolutionarily closer to humans, and we can perhaps more easily relate observations of mouse pathology and behaviors such as locomotion, learning, and memory to their counterparts in humans. However, work from many laboratories has shown that rodent models do not always re- capitulate human disease pathology (Dawson et al. 2010). Drosophila models, however, surprisingly to some, have replicated many pathological processes related to human neurological disorders (Zoghbi and Warren 2010). Next, I outline the advantages that Drosophila melanogaster offers as a model organism, and insights that studies in Drosophila have provided for PD research.

\section{THE ADVANTAGES OF USING DROSOPHILA AS A MODEL SYSTEM TO STUDY PD}

The identification of PD genes provides an unprecedented opportunity to understand PD pathogenesis through in vivo studies. The key questions in the field are: What are the normal functions of these PD genes? How do PD pathogenic mutations affect PD gene function? Do these PD genes function in a common pathway, or in parallel pathways?

Among the various model organisms, Drosophila melanogaster has emerged as an especially effective tool to study PD genes. Drosophila has been used extensively for investigating fundamental biological processes, such as cell death (Hay et al. 2004; Hay and Guo 2006), as well as cell proliferation, growth, and migration (for review, see Bellen et al. 2010). In addition, flies display complex behaviors such as circadian rhythms, learning and memory, sleep, and aggression (Bellen et al. 2010). Some of these were thought to be exclusive to humans, and studies now suggest that the genetic bases of these behaviors are conserved in humans. Accumulated studies from more than a century have left the modern fly field with powerful molecular genetic tools (Adams and Sekelsky 2002; St Johnston 2002; Venken and Bellen 2005). Drosophila also has a compact genome size (1/30th of the human genome), limited genetic redundancy, and a short generation time (10 days) and life span (60-80 days). The complete sequence of the Drosophila genome has revealed that $77 \%$ of human disease genes are conserved in the fly $(\mathrm{Ru}-$ bin 2000; Bier 2005). These features make flies an excellent model system in which to study the function of disease genes including those involved in neurodegenerative diseases (Lessing and Bonini 2009; Lu and Vogel 2009), and in 
M. Guo

which to dissect genetic pathways related to these disease genes.

Drosophila has emerged as an effective tool for studying PD pathogenesis (for review, see Dodson and Guo 2007; Lu and Vogel 2009; Guo 2010; Whitworth 2011). The Drosophila genome encodes homologs of DJ-1, PINK1, PARKIN, LRRK2, and VPS35. The adult brain of Drosophila contains clusters of dopaminergic neurons (Nassel and Elekes 1992), and these neurons degenerate when flies are fed rotenone (Coulom and Birman 2004), a complex I inhibitor that also triggers dopaminergic neuronal degeneration in mammals (Sherer et al. 2003; Bove et al. 2005). Among the genes that mediate familial PD, only $\alpha$-synuclein does not have a homolog in Drosophila. Nevertheless, expression of human wild-type and PD-causing mutant forms of SNCA in Drosophila results in dopaminergic neuronal loss (Feany and Bender 2000; Trinh et al. 2008). In this review, we mainly focus on Drosophila homologs of genes associated with recessive forms of PD: PINK1, PARKIN, and DJ-1. We also emphasize the implications that these studies in Drosophila have for advancing our understanding of PD in clinical settings. It is important to note that although dopaminergic neurons do show slight degeneration in some Drosophila models of PD (Whitworth et al. 2005; Trinh et al. 2008), the significance of Drosophila models of PD involves much more than dopaminergic neuron pathology. Flies show defects in multiple systems, reminiscent of the multiple system involvement in PD patients. It is the understanding of the cellular basis of these defects that will provide insight into the pathogenesis of PD.

\section{VARIOUS TOOLS IN DROSOPHILA}

It would be a chapter in itself to review fully the tools available in Drosophila, but here I summarize those that are particularly relevant to building disease models.

\section{Mutagenesis- and Loss-of-Function- Based Studies}

Transposons including $P$-element, piggyBac, and Minos can insert in either coding sequence or regulatory regions of a gene resulting in loss of function of the gene. The advantage of using $P$ elements, and possibly Minos, is that one can generate a null mutation via imprecise excision of $P$-elements located near or in a gene (Adams and Sekelsky 2002). The fly community has generated a large number of transposon insertion lines, and their precise insertion sites in the genome have been determined (Bellen et al. 2004; Thibault et al. 2004). It is estimated that in the next several years, collectively, transposon insertions will be available to disrupt $>90 \%$ of all Drosophila genes. The availability of these transposons has largely replaced the need for chemical mutagenesis, which requires lengthy and tedious mapping strategies. In genomic areas in which transposable elements are lacking, one can perform homologous recombination to generate deletions or disease-related knockin alleles (Rong and Golic 2000; Wesolowska and Rong 2010).

\section{Tissue-Specific Overexpression and Knockdown Can Be Easily Accomplished In Vivo}

Temporally controlled, tissue-specific overexpression can be easily accomplished in vivo using the UAS-GAL4 system, a bipartite transcription activation system (Brand and Perrimon 1993). In this system, one transgene consists of a yeast transcription factor (GAL4), driven by a ubiquitous promoter such as tubulin or a tissue-specific promoter such as the dopaminergic neuron-specific TH. The second transgene consists of a gene of interest that is under the control of UAS (upstream activating sequences), which drives transcription in response to GAL4 binding. Therefore, for example, transgenic flies carrying a version of Gal4 driven by the tyrosine hydroxylase promoter (TH-Gal4) and UASPINK1 will express PINK1 in a dopaminergic neuron-specific pattern. This versatile system allows expression of genes both during development and adulthood, which is very useful for modeling diseases. More recently, several variants on this two-component expression system have been generated. (These are reviewed in detail elsewhere.) Suffice it to say that they allow one to turn gene expression on (or off; see below) 
in almost any desired tissue or cell type, in an inducible manner (del Valle Rodriguez et al. 2012). Transposon mutagenesis has also resulted in the creation of a large number of $P$-elementbearing lines that carry a UAS element near one end. These lines, known as EP lines, allow for GAL4-dependent expression of nearby genes, if the UAS element is $5^{\prime}$ to the gene, and pointing so as to drive expression of the gene (Rorth 1996).

Tissue-specific and inducible gene silencing can be accomplished through the use of the GAL4 system as well. In brief, flies can be generated that carry UAS-transgenes expressing long double-stranded RNAs (dsRNAs) or microRNAs. When crossed to specific GAL4 drivers or the many variants referenced above, gene silencing is brought about in cells expressing GAL4. Lines of flies carrying UAS-dsRNA or UAS-microRNA transgenes have been, or are being, generated for most Drosophila genes (Dietzl et al.2007; Ni et al.2011). These lines are publicly available.

\section{Site-Specific Transgenesis Allows Precise Controls over Genetic Background and Expression Levels}

Site-specific gene integration can also be brought about using donor plasmids carrying target sites for a site-specific integrase, and fly lines carrying a source of integrase and a "landing pad" target site inserted at specific positions in the genome. Multiple versions of site-specific integration technology and landing pads scattered throughout the genome are available for the fly (Venken and Bellen 2007; del Valle Rodriguez et al. 2012). This technology is important because it allows one to test the activity of a series of mutant proteins, for example, having confidence that all other genomic variables have been kept constant.

Genetics and Compound Screens Provide Unbiased Methods for Identifying Genes and Pathways Important for PD Pathogenesis and Its Suppression

One of the most important tools in the Drosophila toolbox lies in the ability to perform largescale screens for new mutations or conditions of gene overexpression or silencing that enhance or suppress phenotypes associated with disease models. A number of screen strategies are available (for review, see St Johnston 2002). The goal of unbiased genetic screens is to identify new components that either function in the same genetic pathway of the disease model or in parallel pathways to regulate a common process (the disease state). The power of these screens cannot be understated, because they do not require any existing knowledge related to the function of the disease gene.

In parallel, Drosophila has also become a valuable in vivo model in which to perform compound screens for suppressors of disease states (Gladstone and Su 2011; Pandey and Nichols 2011). In vivo systems like the fly are advantageous for several reasons. First, flies are cheap as compared with mammalian disease models such as mice and show disease phenotypes during development or as young adults. Second, many disease states cannot be easily modeled in cell culture. Third, and perhaps most importantly, in vivo screens are unbiased in that they focus on the bottom line-suppression of the disease state. This stands in contrast to many cell-based compound screens, which focus on identifying inhibitors or activators of a particular protein. Although obviously a valuable approach, focus on modifying the activity of a particular protein commits the researcher to that molecule, to the exclusion of all other pathways and molecules, many of which may not be known as regulators of the disease state under study. It may be particularly challenging to implement specific target-based drug screens in cell culture for diseases that result from loss of gene function, as with several of the familial forms of PD, because in these cases one must know the identity of a pharmacologically relevant target in another gene ahead of time.

\section{WHAT LESSONS HAVE WE LEARNED FROM STUDIES IN DROSOPHILA?}

PINK1 and Parkin Function in a Common Pathway to Regulate Mitochondrial Integrity

PARKIN encodes a protein with RING-finger motifs and has E3 ubiquitin ligase activity in 
M. Guo

in vitro assays. The initial hypothesis related to PARKIN function was that loss of parkin resulted in the aberrant accumulation of toxic proteins, perhaps as a result of a failure of the ubiquitin-proteasome system to degrade substrates of Parkin ubiquitination. Consistent with this hypothesis, Parkin catalyzes K48-mediated polyubiquitination, which targets substrates for proteasomal degradation, and multiple proteins have been shown to interact with Parkin and are ubiquitinated in a Parkin-dependent manner in vitro. However, few of these substrates have been shown to accumulate in vivo, in PARK2 patients, or parkin knockout mice, leaving their significance unclear (for review, see West et al. 2007; Dawson and Dawson 2010). Subsequent studies indicated that Parkin also catalyzes other forms of ubiquitination (for review, see West et al. 2007), which can influence cellular processes such as signal transduction, transcriptional regulation, and protein and membrane trafficking, without promoting substrate degradation (Mukhopadhyay and Riezman 2007). However, the exact role of Parkin remained unclear.

The first in vivo indication that parkin regulates mitochondrial integrity came from studies of Drosophila parkin mutants. Flies lacking parkin show dramatic mitochondrial defects in several energy-intensive tissues (Greene et al. 2003; Pesah et al. 2004), and a subset of dopaminergic neurons undergoes degeneration (Whitworth et al. 2005). Subsequent studies in parkin knockout mice indicated that although severe defects in mitochondrial morphology are not observed, these animals do display defects in mitochondrial respiration (Palacino et al. 2004).

Key studies that implicate mitochondrial dysfunction as a central mechanism for PD pathogenesis come from studies of Drosophila PINK1 and its interaction with the fly parkin. PINK1 encodes a protein with a mitochondrial targeting sequence and a serine-threonine kinase domain. We and others reported that a large fraction of PINK1 is localized to mitochondria (Clark et al. 2006), and Drosophila lacking PINK1 show phenotypes very similar to those of flies lacking parkin. PINK1 and parkin mutants are viable but show striking defects in mitochondrial integrity-swollen mitochondria that have severely broken cristae-in energy-intense tissues. The males are sterile, adult muscle undergoes degeneration and cell death, and a subset of dopaminergic neurons undergoes degeneration (Clark et al. 2006; Park et al. 2006; Yang et al. 2006). PINK1 mutants also show reduced ATP levels and mitochondrial DNA (mtDNA) content, and increased stress sensitivity (Clark et al. 2006; Park et al. 2006; Yang et al. 2006). Flies lacking endogenous PINK1 function but expressing PD-associated mutant forms of PINK1, either by overexpression (Yang et al. 2006) or under the control of the endogenous PINK1 promoter (Yun et al. 2008), show phenotypes similar to those of PINK1-null mutants, consistent with PINK1-associated disease being the result of loss of function.

What is the relationship between PINK1 and parkin? Stringent genetic studies in Drosophila allow one to construct a genetic pathway. parkin overexpression in flies suppresses all PINK1 mutant phenotypes tested (Clark et al. 2006; Park et al. 2006; Yang et al. 2006), whereas PINK1 overexpression does not compensate for loss of parkin function (Clark et al. 2006; Park et al. 2006). Furthermore, double mutants lacking both PINK1 and parkin have phenotypes identical to, rather than stronger than, either single mutant (Clark et al. 2006; Park et al. 2006; Yang et al. 2006). In addition, several groups have reported that Parkin and PINK1 can physically interact in at least some contexts (Kim et al. 2008; Xiong et al. 2009; Sha et al. 2010). Together, these observations provide compelling in vivo evidence that PINK1 and parkin act in a linear pathway to regulate mitochondrial integrity and maintenance, with parkin functioning downstream from PINK1.

Several lines of evidence suggest that these observations on PINK1 and parkin function in flies are relevant to humans. First, PD patients who harbor mutations in PINK1 or PARKIN are clinically indistinguishable (Ibanez et al. 2006), and mice lacking both PINK1 and parkin show phenotypes no worse than those of the single mutants (Kitada et al. 2009), consistent with the hypothesis that these genes function in a common genetic pathway. Second, expression of human PINK1 (Clark et al. 2006; Yang et al. 2006) 
or PARKIN in Drosophila suppresses phenotypes caused by loss of function of PINK1 or parkin, respectively, suggesting that the human and fly proteins are functionally conserved. Third, cells from patients and/or mouse knockout models of PINK1 or parkin also show defects in mitochondrial morphology and/or mitochondrial respiration, particularly in complex I activity in a variety of cell types (Greene et al. 2003; Muftuoglu et al. 2004; Palacino et al. 2004; Exner et al. 2007; Hoepken et al. 2007; Stichel et al. 2007; Gautier et al. 2008; Poole et al. 2008; Wood-Kaczmar et al. 2008; Dagda et al. 2009; Gegg et al. 2009; Morais et al. 2009; Sandebring et al. 2009; Grünewald et al. 2010; Billia et al. 2011; Schmidt et al. 2011; Shim et al. 2011). Fourth, in neurons derived from pluripotent stem cells from PD patients harboring PINK1 mutations, recruitment of Parkin to mitochondria is impaired (Seibler et al. 2011).

It is important to note that, in contrast to prior toxin models of PD in which dopaminergic neurons are selectively killed, PINK1 or parkin genetic models lead to defects in multiple tissues in addition to those in dopaminergic neurons, which are largely degenerative in nature. Therefore, these genetic models have the potential to uncover new therapies for neuroprotection, as well as targeting the cellular defects that cause cell loss in both dopaminergic neurons and non-dopaminergic tissues.

\section{The PINK1/Parkin Pathway Promotes Mitochondrial Fission and/or Inhibits Fusion}

How do PINK1 and parkin regulate mitochondrial function? Examination of PINK1 and parkin mutant phenotypes provided an important clue. During Drosophila spermatogenesis, mitochondria in spermatids undergo mitochondrial fusion, creating a spherical structure composed of two intertwined mitochondria. Subsequently, the structure unfurls, yielding two mitochondrial derivatives. In both PINK1 and parkin mutants, however, only one mitochondrial derivative is seen, suggesting a defect in mitochondrial fission or an overabundance of fusion (Riparbelli and Callaini 2006; Deng et al. 2008).

Mitochondria are dynamic and continually undergoing cycles of fission and fusion. Mitochondrial fusion is promoted by mitofusin $(m f n)$, which is required for outer membrane fusion, and Optic atrophy 1 (Opa-1), which is essential for inner membrane fusion. Mitochondrial fission is promoted by Dynamin-related Protein 1 (Drp1), a predominantly cytoplasmic protein recruited to mitochondria during fission (for review, see Chen and Chan 2009).

Several key findings support the hypothesis that the PINK1/parkin pathway regulates mitochondrial dynamics. First, mitochondria in PINK1 or parkin mutants are clumped in both dopaminergic neurons and flight muscle. They are also swollen and have disrupted cristae. Second, these cellular defects in mitochondrial morphology, as well as other defects such as the degeneration of flight muscle, cell death, locomotion defects, and a decrease in dopamine levels in fly heads, can be suppressed by increasing the expression of the pro-fission molecules $d r p 1$, and/or decreasing levels of the pro-fusion molecules mitofusin or opa1 (Deng et al. 2008; Poole et al. 2008; Yang et al. 2008; Park et al. 2009). Third, loss of PINK1 function leads to defects in assembly of the electron transport chain, which can be rescued by overexpression of $d r p 1$ (Liu et al. 2011). Fourth, heterozygosity for $d r p 1$ is lethal in a PINK1 mutant background, consistent with the idea that PINK1 and $d r p 1$ work in the same direction to promote fission (Deng et al. 2008; Poole et al. 2008). That said, it is important to note that the phenotypes associated with loss of PINK1 or parkin, and loss of $d r p 1$, are distinct (Deng et al. 2008), indicating that PINK1 and Parkin are not core components of the fission machinery, but instead regulators of the process. Molecular mechanisms of how this is accomplished are suggested in part by studies showing that Parkin can ubiquitinate and degrade Mfn (Poole et al. 2010; Ziviani et al. 2010). Because both cellular defects and organismal defects can be rescued by manipulating mitochondrial dynamics, manipulation of mitochondrial dynamics provides a novel therapeutic strategy. 
M. Guo

Observations that point to roles of PINK1 and parkin in regulating mitochondrial morphology have also been obtained in mammalian systems. However, in contrast to the story in Drosophila, which is consistent across cell types and laboratories, in mammalian systems various effects have been observed. Some studies suggest that loss of PINK1 results in fission, with decreased levels of $d r p 1$ resulting in suppression (Exner et al. 2007; Dagda et al. 2009; Lutz et al. 2009; Sandebring et al. 2009). In other studies, however, enlarged mitochondria have been observed in PINK1 striatal neurons (Gautier et al. 2008), and in COS7 cells mitochondrial phenotypes associated with PINK1 knockdown are suppressed by fis 1 or $d r p 1$ overexpression, as in Drosophila (Yang et al. 2008). Moreover, the PINK1/parkin pathway promotes $d r p 1$-dependent mitochondrial fission and/or inhibits opal-dependent fusion in primary neurons, mammalian hippocampal, and dopaminergic neurons (Yu et al. 2011). In addition, in fibroblasts from patients with PINK1 or PARKIN mutations, Mfn ubiquitination is affected (Rakovic et al. 2011). These studies, in conjunction with those suggesting that Mfn is degraded by Parkin in mammalian cells (Chan et al. 2011; Tanaka et al. 2011), suggest that the PINK1 / parkin pathway is likely to play a conserved role in mammals. The reasons for the differences in how loss of PINK1/parkin results in defects in mitochondrial fusion and fission are not entirely clear. But it is likely that the final mitochondrial morphology phenotype observed in any particular cell type, particularly with respect to the presence or absence of PINK1/parkin, will depend on many variables. In any case, what is most important is not the specific morphology observed, but the functional state of the mitochondrial population and the ways in which this is influenced by PINK1 and parkin. Recent observations in mammals and flies detailed below have provided several important insights.

\section{PINK1 and Parkin Promote Mitophagy}

In a series of elegant studies, Youle and colleagues showed that in mammalian cells, Parkin is recruited to mitochondria whose inner mem- brane has been depolarized (an outcome common to multiple forms of mitochondrial damage), or that have been treated with the herbicide Paraquat, an inducer of complex-1-dependent reactive oxygen species (Narendra et al. 2008). Recruitment of Parkin was followed by removal of these damaged mitochondria through a specialized form of autophagy known as mitophagy, in which mitochondria are specifically degraded following engulfment by autophagosomes (for review, see Goldman et al. 2010). Recent findings suggest that mitophagy is intimately linked with changes in mitochondrial size and shape brought about through fission and fusion (for review, see Hyde et al. 2010). Mitophagy requires both the loss of fusion and the presence of fission. Importantly, decreased mitophagy results in the accumulation of oxidized proteins and decreased cellular respiration, strongly suggesting that the end result of this process is the selective removal of damaged mitochondria (Twig et al. 2008). Mitophagy, but not recruitment of Parkin to depolarized mitochondria, requires Drp1, indicating that Parkindependent mitophagy requires fission (Narendra et al. 2008).

Work in flies and mammals further shows that recruitment of Parkin to mitochondria depends on PINK1 (Narendra et al. 2009; Geisler et al. 2010; Vives-Bauza et al. 2010; Ziviani et al. 2010). Parkin fails to be recruited to depolarized mitochondria in cells lacking PINK1. PINK1's ability to recruit Parkin requires PINK1 kinase activity. In flies, early work suggested a role for PINK1-dependent phosphorylation of Parkin as important for recruitment (Kim et al. 2008). Follow-up studies in mammalian cells have yielded conflicting results. In one study, PINK1 was shown to phosphorylate Parkin, but in a second study, no evidence was found for binding of PINK1 to Parkin, phosphorylation of Parkin by PINK1, or ubiquitination of PINK1 by Parkin (Vives-Bauza et al. 2010).

How does PINK1 promote the recruitment of Parkin specifically to damaged mitochondria? PINK1 protein levels are specifically upregulated on damaged mitochondria (Narendra et al. 2009; Vives-Bauza et al. 2010; Ziviani et al. 2010). PINK1 is a membrane protein with its 
carboxyl terminus facing the cytoplasm (Zhou et al. 2008). In healthy mitochondria, PINK1 is constitutively cleaved, releasing its carboxy-terminal kinase domain into the cytoplasm, where it is degraded in a proteasome-dependent manner. In damaged mitochondria that have lost their membrane potential, cleavage decreases and full-length PINK1 remains anchored to the membrane (Narendra et al. 2009). Mitochondrial anchorage is all that is required, because tethering of PINK1 to the mitochondrial membrane through other methods is sufficient to recruit Parkin (Narendra et al. 2009). As expected based on these observations, overexpression of PINK1 in a wild-type background, but not a parkin mutant background, is also sufficient to promote Parkin recruitment (VivesBauza et al. 2010; Ziviani et al. 2010). In cultured Drosophila cells, recruitment of Parkin results in the ubiquitination and removal of Mfn, whereas loss of PINK1 and parkin results in accumulation of Mfn (Poole et al. 2010; Ziviani et al. 2010). Ubiquitination of Mfn may function to prevent outer mitochondrial membrane fusion, thus facilitating the segregation and isolation of damaged mitochondria. Ubiquitinated Mfn may also serve as a signal for mitophagy, because loss of mitofusin in Drosophila results in decreased recruitment of Parkin to mitochondria (Ziviani et al. 2010), suggesting that these proteins may be involved in recruitment as well.

Once recruited and activated, Parkin has several effects on the mitochondria-associated proteome. In addition to Mfns, many mitochondrial proteins are ubiquitinated and/or degraded in a Parkin-dependent manner. These include Milton and Miro (Chan et al. 2011), Bcl-2 (Chen et al. 2010), components of the TOM mitochondrial protein import complex (Chan et al. 2011; Yoshii et al. 2011), VDAC (Geisler et al. 2010; Narendra et al. 2010a), and Drp-1 (Wang et al. 2011a).

How is PINK1 cleavage regulated? Early work in Drosophila showed that PINK1 cleavage required the inner mitochondrial membrane protease rhomboid 7 (Whitworth et al. 2008). This, coupled with an earlier observation that the rhomboid-7 mutant phenotype includes a loss of mitochondrial fusion (McQuibban et al.
2006), suggested a model in which PINK1's profission activity is negatively regulated through cleavage by rhomboid 7. Early experiments in mammalian systems excluded the rhomboid protease PARL as the protease cleaving PINK1 based on the results of RNAi knockdown (Narendra et al. 2010b). However, more recent observation by the same group (Jin et al. 2010) and others (Deas et al. 2011; Meissner et al. 2011a; Shi et al. 2011) clearly show that PINK1 is cleaved by PARL and that this activity is regulated by mitochondrial membrane potential.

Although these findings are intriguing, it is important to note that the recruitment of Parkin to mitochondria in Drosophila and mammalian studies has been performed in cell lines (Ziviani et al. 2010). It remains to be shown that recruitment of Parkin occurs in vivo in tissues that show phenotypes when PINK1/parkin are removed, and that this is associated with mitophagy.

The findings that the PINK1/parkin pathway regulates mitochondrial dynamics and mitophagy suggest an exciting model in which a failure of mitochondrial quality control lies at the heart of PD pathogenesis. In this model, when mitochondria undergo damage, PINK1 senses the damage, becomes stabilized, and recruits Parkin specifically to the damaged mitochondria. Parkin then promotes degradation of Mitofusin, which prevents these mitochondria from fusing with the network. Parkin-dependent ubiquitination of other substrates then results in mitophagy. In PINK1/parkin-mediated $\mathrm{PD}$, damaged mitochondria fail to be cleared, allowing damaged mitochondria, which may carry mutant genomes, to accumulate in cells.

\section{The PINK1/Parkin Pathway and Mitochondrial Transport}

Observations in Drosophila have also led the way in identifying links between PINK1, parkin, and mitochondrial motility. Mitochondria are not located randomly in cells. They are actively trafficked to regions of the cell where ATP or $\mathrm{Ca}^{2+}$ buffering demands are high using a microtubule-based system. Two proteins that mediate microtubule-based transport of mitochondria, 
M. Guo

Miro and Milton, were first identified in Drosophila, in screens for mutants with defects in synaptic transmission and locomotion (Stowers et al. 2002; Guo et al. 2005). Miro sits in the mitochondrial outer membrane (Fransson et al. 2006), and Milton links Miro-bound mitochondria to Kinesin-1-heavy chain, which promotes mitochondrial movement on microtubules (Glater et al. 2006). Thus, in mutants for these genes, mitochondria accumulate in the soma and fail to be transported to axons and dendrites. Miro also functions as a $\mathrm{Ca}^{2+}$ sensor, promoting the release of mitochondria from microtubules in areas of the cell with high levels of intracellular $\mathrm{Ca}^{2+}$ (Cai and Sheng 2009).

Recent observations from Drosophila and mammalian laboratories show that mitochondrial PINK1 binds Miro (Weihofen et al. 2009; Wang et al. 2011b; Liu et al. 2012). This leads, either through phosphorylation (Wang et al. 2011 b) or through a phosphorylation-independent mechanism (Liu et al. 2012), to Parkindependent ubiquitination and degradation of Miro, resulting in a loss of mitochondrial movement. Other work has shown that Miro is lost from depolarized mitochondria (Chan et al. 2011), stationary mitochondria are less likely than motile mitochondria to undergo fusion (Twig and Shirihai 2011), and that loss of Miro promotes mitophagy (Liu et al. 2012). Together these observations suggest that PINK1 and Parkin are important regulators of mitochondrial motility, and that one of their functions in mitochondrial quality control is to sequester damaged mitochondria by severing their connections to the microtubule network, preparing them for autophagy. Such an activity is likely to be particularly important in neurons with long processes.

\section{Links between the PINK1/Parkin Pathway and Other PARK Loci}

Omi/HtrA2 (PARK13) encodes a serine protease (Vande Walle et al. 2008) that is localized to the mitochondrial matrix. Omi/HtrA2 has been suggested to function downstream from PINK1 in a common pathway (Plun-Favreau et al. 2007), based on the findings that mammalian
Omi/HtrA2 binds PINK1 and that the phosphorylation of Omi/HtrA2 is dependent on PINK1 in mammalian cells (Plun-Favreau et al. 2007). One group has also reported the presence of mutations/polymorphisms in Omi/ HtrA2 in sporadic PD patients (Strauss et al. 2005). Loss of Omi/HtrA2 leads to loss of nondopaminergic neurons in the striatum (RathkeHartlieb et al. 2002; Jones et al. 2003; Martins et al. 2004).

Does Omi/HtrA2 function as a downstream target of PINK1 in vivo? An overexpressionbased genetic interaction is observed between PINK1 and omi/HtrA2 (Whitworth et al. 2008; Yun et al. 2008). However, in contrast to PINK1 mutants, omi/HtrA2-null mutants have normal mitochondrial morphology in both muscle and testes, and a normal number of dopaminergic neurons (Yun et al. 2008). In addition, extensive loss-of-function-based genetic interaction studies fail to provide any in vivo evidence supporting the hypothesis that $\mathrm{Omi} / \mathrm{HtrA} 2$ functions in the same pathway, either upstream or downstream of PINK1, to either positively or negatively regulate $P I N K 1$. They also do not provide any clear evidence that Omi/HtrA2 acts in a parallel manner to regulate mitochondrial morphology (Yun et al. 2008). These loss-of-function-based analyses are more relevant to PD than are Omi/ HtrA2 overexpression-based analyses, because reported Omi/HtrA2 mutations associated with PD are proposed to represent loss-of-function or dominant-negative mutations (Strauss et al. 2005). In addition, mutant forms of the Drosophila Omi/HtrA2 analogous to the reported disease form in sporadic PD patients, and a mutant lacking a serine thought to be a target for PINK1-dependent phosphorylation (PlunFavreau et al. 2007), retain significant, if not full, Omi/HtrA2 function in vivo (Yun et al. 2008). Thus, loss-of-function studies strongly suggest that Omi/HtrA2 does not play an essential role in regulating mitochondrial integrity in the PINK1/parkin pathway in Drosophila (Yun et al. 2008). Recent studies in mice show that neurodegeneration in the Omi/HtrA2 mutant is not rescued by overexpression of parkin in mice (Yoshida et al. 2010). The implication of these studies is that Omi/HtrA2 may not 
function in the PINK1/parkin pathway. This conclusion is also supported by studies that found no association between mutations in Omi/HtrA2 and PD, and work showing that the PD-associated mutation in Omi/HtrA2 occurs with comparable frequency in unaffected populations, suggesting they represent simple polymorphisms (Ross et al. 2008; Simon-Sanchez and Singleton 2008).

Mutations in DJ-1 (PARK7) cause very rare autosomal-recessive forms of PD (Bonifati et al. 2003). Many diverse activities have been proposed for $D J$ - 1 , including functions as a cysteine protease, a redox-regulated chaperone, a transcription coactivator and RNA-binding protein, and a regulator of survival signaling through interactions with Daxx or the kinase ASK1 (for review, see Wilson 2011). What is clear is that DJ1 is cytoprotective and that this activity requires a conserved cysteine. Although DJ-1 is predominantly cytoplasmic, oxidative stress enhances its association with mitochondria (Canet-Aviles et al. 2004; Blackinton et al. 2005, 2009; Ooe et al. 2005; Levet al. 2008). In addition, versions ofDJ1 targeted specifically to mitochondria by fusing a mitochondrial localization sequence to its amino terminus show enhanced cytoprotective functions, suggesting that the mitochondria is one (of perhaps many) important site of DJ-1 action (Junn et al. 2009). Finally, it is worth noting that triple knockout mice lacking PINK1, parkin, and DJ-1 fail to show nigral degeneration, even with aging (Kitada et al. 2009). This somewhat surprising result could reflect action in a common pathway as with PINK1 and parkin. Alternatively, it could reflect developmental compensation, the presence of which is strongly hinted at in experiments using conditional, adult-specific parkin knockout mice (Shin et al. 2011; cf. Goldberg et al. 2003; Itier et al. 2003; Von Coelln et al. 2004; Perez and Palmiter 2005).

In Drosophila, flies lacking DJ-1 (deletions) are viable, with their most prominent phenotype being increased sensitivity to oxidative stress as assayed by reduced survival upon Paraquat or rotenone feeding (Menzies et al. 2005; Meulener et al. 2005, 2006). In some studies, overexpression of DJ-1 fails to rescue PINK1 mutant muscle phenotypes (Yang et al. 2006) or male sterility due to lack of PINK1 or parkin (M Guo, unpubl.). In other studies, Drosophila DJ-1 mutants show mitochondrial defects, but these are in many ways distinct from those associated with loss of PINK1 or parkin (Hao et al. 2010). In addition, although expression of $D J-1$ is capable of rescuing muscle defects due to loss of PINK1, it cannot rescue identical-looking muscle defects due to loss of parkin. Expression of either PINK1 or Parkin in a DJ-1 mutant also has the surprising effect of causing organismal lethality. All of these results suggest complex, not linear, interactions between $D J-1$ and the PINK1/parkin pathway.

\section{CONTRIBUTIONS OF DROSOPHILA AND FUTURE DIRECTIONS}

In summary, work in Drosophila has provided several key insights in understanding PD. Flies provided the first in vivo evidence that PINK1 and parkin regulate mitochondrial integrity. The stringent epistatic studies provided compelling evidence that PINK1 and parkin function in a common genetic pathway, with PINK1 positively regulating parkin. In contrast, studies have not provided in vivo support for Omi/HtrA2 as a component of the PINK1/parkin pathway. Studies in Drosophila also suggest that the PINK1/parkin pathway promotes mitochondrial fission and/or inhibits fusion. These studies provide the first demonstration that manipulation of mitochondrial dynamics can suppress PINK1/parkin phenotypes both at the cellular level (mitochondrial integrity) and organismal level (muscle degeneration, dopamine levels, and locomotion), thereby providing novel therapeutic targets. More recent work in cultured cells shows that PINK1 and parkin regulate mitophagy in Drosophila, paralleling work in mammals and suggesting the exciting possibility that failure of mitophagy, and thus mitochondrial quality control, underlies the pathogenesis of PINK1/parkin-mediated PD. The unique attributes of Drosophila (robust phenotypes, straightforward genetics providing opportunities for genome-wide genetic screens and drug screens) suggest that Drosophila studies will continue to move the field forward and help identify 
M. Guo

novel therapies for $\mathrm{PD}$, and potentially other aging-related neurodegenerative disorders. In support of this contention, compounds and a number of genes (either over- or underexpressed, or exogenous) have been identified as suppressors of PINK1 and/or parkin phenotypes in the fly (Greene et al. 2005; Whitworth et al. 2005; Deng et al. 2008; Poole et al. 2008; Yang et al. 2008; Park et al. 2009; Tain et al. 2009; Hao et al. 2010; Imai et al. 2010; Liu and Lu 2010; Fernandes and Rao 2011; Saini et al. 2011; Koh et al. 2012; Vilain et al. 2012). Given that defects in mitochondria accumulate in normal aging as well as in PD, identifying multiple ways of activating mitophagy may be generally useful therapeutically in many diseases of aging. In short, Drosophila provides an indispensable and unique opportunity to contribute to the PD field.

\section{ACKNOWLEDGMENTS}

I apologize to those whose work has not been cited because of space constraints. I thank the Guo laboratory members and Bruce Hay for discussions. This work is supported by grants and funds from the National Institutes of Health (R01, K02), the Glenn Family Foundation, the Esther A. and Joseph Klingenstein Fellowship (Robert H. Ebert Clinical Scholar), and the McKnight Foundation of Neuroscience.

\section{REFERENCES}

Abou-Sleiman PM, Muqit MM, Wood NW. 2006. Expanding insights of mitochondrial dysfunction in Parkinson's disease. Nat Rev Neurosci 7: 207-219.

Adams MD, Sekelsky JJ. 2002. From sequence to phenotype: Reverse genetics in Drosophila melanogaster. Nat Rev Genet 3: 189-198.

Bellen HJ, Levis RW, Liao G, He Y, Carlson JW, Tsang G, Evans-Holm M, Hiesinger PR, Schulze KL, Rubin GM, et al. 2004. The BDGP gene disruption project: Single transposon insertions associated with $40 \%$ of Drosophila genes. Genetics 167: 761-781.

Bellen HJ, Tong C, Tsuda H. 2010. 100 years of Drosophila research and its impact on vertebrate neuroscience: A history lesson for the future. Nat Rev Neurosci 11: 514-522.

Bier E. 2005. Drosophila, the golden bug, emerges as a tool for human genetics. Nat Rev Genet 6: 9-23.
Billia F, Hauck L, Konecny F, Rao V, Shen J, Mak TW. 2011. PTEN-inducible kinase 1 (PINK1)/Park6 is indispensable for normal heart function. Proc Natl Acad Sci 108: 9572-9577.

Blackinton J, Ahmad R, Miller DW, van der Brug MP, CanetAviles RM, Hague SM, Kaleem M, Cookson MR. 2005. Effects of DJ-1 mutations and polymorphisms on protein stability and subcellular localization. Brain Res Mol Brain Res 134: 76-83.

Blackinton J, Lakshminarasimhan M, Thomas KJ, Ahmad R, Greggio E, Raza AS, Cookson MR, Wilson MA. 2009. Formation of a stabilized cysteine sulfinic acid is critical for the mitochondrial function of the parkinsonism protein DJ-1. J Biol Chem 284: 6476-6485.

Bonifati V, Rizzu P, van Baren MJ, Schaap O, Breedveld GJ, Krieger E, Dekker MC, Squitieri F, Ibanez P, Joosse M, et al. 2003. Mutations in the DJ-1 gene associated with autosomal recessive early-onset parkinsonism. Science 299: 256-259.

Bove J, Prou D, Perier C, Przedborski S. 2005. Toxin-induced models of Parkinson's disease. NeuroRx 2: 484-494.

Braak H, Del Tredici K, Rub U, de Vos RA, Jansen Steur EN, Braak E. 2003. Staging of brain pathology related to sporadic Parkinson's disease. Neurobiol Aging 24: 197211.

Brand AH, Perrimon N. 1993. Targeted gene expression as a means of altering cell fates and generating dominant phenotypes. Development 118: 401-415.

Cai Q, Sheng ZH. 2009. Moving or stopping mitochondria: Miro as a traffic cop by sensing calcium. Neuron 61: $493-$ 496.

Canet-Aviles RM, Wilson MA, Miller DW, Ahmad R, McLendon C, Bandyopadhyay S, Baptista MJ, Ringe D, Petsko GA, Cookson MR. 2004. The Parkinson's disease protein DJ-1 is neuroprotective due to cysteine-sulfinic acid-driven mitochondrial localization. Proc Natl Acad Sci 101: 9103-9108.

Chan NC, Salazar AM, Pham AH, Sweredoski MJ, Kolawa NJ, Graham RL, Hess S, Chan DC. 2011. Broad activation of the ubiquitin-proteasome system by Parkin is critical for mitophagy. Hum Mol Genet 20: 1726-1737.

Chartier-Harlin MC, Dachsel JC, Vilarino-Guell C, Lincoln SJ, Lepretre F, Hulihan MM, Kachergus J, Milnerwood AJ, Tapia L, Song MS, et al. 2011. Translation initiator EIF4G1 mutations in familial Parkinson disease. Am J Hum Genet 89: 398-406.

Chen H, Chan DC. 2009. Mitochondrial dynamics-fusion, fission, movement, and mitophagy - in neurodegenerative diseases. Hum Mol Genet 18: R169-R176.

Chen D, Gao F, Li B, Wang H, Xu Y, Zhu C, Wang G. 2010. Parkin mono-ubiquitinates $\mathrm{Bcl}-2$ and regulates autophagy. J Biol Chem 285: 38214-38223.

Clark IE, Dodson MW, Jiang C, Cao JH, Huh JR, Seol JH, Yoo SJ, Hay BA, Guo M. 2006. Drosophila pink1 is required for mitochondrial function and interacts genetically with parkin. Nature 441: 1162-1166.

Coulom H, Birman S. 2004. Chronic exposure to rotenone models sporadic Parkinson's disease in Drosophila melanogaster. J Neurosci 24: 10993-10998.

Dagda RK, Cherra SJ III, Kulich SM, Tandon A, Park D, Chu CT. 2009. Loss of PINK1 function promotes mitophagy 
through effects on oxidative stress and mitochondrial fission. J Biol Chem 284: 13843-13855.

Dauer W, Przedborski S. 2003. Parkinson's disease: Mechanisms and models. Neuron 39: 889-909.

Dawson TM, Dawson VL. 2010. The role of parkin in familial and sporadic Parkinson's disease. Mov Disord 25: S32-S39.

Dawson TM, Ko HS, Dawson VL. 2010. Genetic animal models of Parkinson's disease. Neuron 66: 646-661.

Deas E, Plun-Favreau H, Gandhi S, Desmond H, Kjaer S, Loh SH, Renton AE, Harvey RJ, Whitworth AJ, Martins LM, et al. 2011. PINK1 cleavage at position A103 by the mitochondrial protease PARL. Hum Mol Genet 20: 867 879.

del Valle Rodriguez A, Didiano D, Desplan C. 2012. Power tools for gene expression and clonal analysis in Drosophila. Nat Methods 9: 47-55.

Deng H, Dodson MW, Huang H, Guo M. 2008. The Parkinson's disease genes pinkl and parkin promote mitochondrial fission and/or inhibit fusion in Drosophila. Proc Natl Acad Sci 105: 14503-14508.

Dietzl G, Chen D, Schnorrer F, Su KC, Barinova Y, Fellner M, Gasser B, Kinsey K, Oppel S, Scheiblauer S, et al. 2007. A genome-wide transgenic RNAi library for conditional gene inactivation in Drosophila. Nature 448: 151-156.

Dodson MW, Guo M. 2007. Pink1, Parkin, DJ-1 and mitochondrial dysfunction in Parkinson's disease. Curr Opin Neurobiol 17: 331-337.

Exner N, Treske B, Paquet D, Holmstrom K, Schiesling C, Gispert S, Carballo-Carbajal I, Berg D, Hoepken HH, Gasser T, et al. 2007. Loss-of-function of human PINK1 results in mitochondrial pathology and can be rescued by parkin. J Neurosci 27: 12413-12418.

Feany MB, Bender WW. 2000. A Drosophila model of Parkinson's disease. Nature 404: 394-398.

Fernandes C, Rao Y. 2011. Genome-wide screen for modifiers of Parkinson's disease genes in Drosophila. Mol Brain 4: 17.

Fransson S, Ruusala A, Aspenstrom P. 2006. The atypical Rho GTPases Miro-1 and Miro-2 have essential roles in mitochondrial trafficking. Biochem Biophys Res Commun 344: $500-510$

Gautier CA, Kitada T, Shen J. 2008. Loss of PINK1 causes mitochondrial functional defects and increased sensitivity to oxidative stress. Proc Natl Acad Sci 105: $11364-$ 11369.

Gegg ME, Cooper JM, Schapira AH, Taanman JW. 2009. Silencing of PINK1 expression affects mitochondrial DNA and oxidative phosphorylation in dopaminergic cells. PLoS ONE 4: e4756.

Geisler S, Holmstrom KM, Skujat D, Fiesel FC, Rothfuss OC, Kahle PJ, Springer W. 2010. PINK1/Parkin-mediated mitophagy is dependent on VDAC1 and p62/ SQSTM1. Nat Cell Biol 12: 119-131.

Gladstone M, Su TT. 2011. Chemical genetics and drug screening in Drosophila cancer models. J Genet Genomics 38: $497-504$.

Glater EE, Megeath LJ, Stowers RS, Schwarz TL. 2006. Axonal transport of mitochondria requires Milton to recruit kinesin heavy chain and is light chain independent. J Cell Biol 173: 545-557.
Goldberg MS, Fleming SM, Palacino JJ, Cepeda C, Lam HA Bhatnagar A, Meloni EG, Wu N, Ackerson LC, Klapstein GJ, et al. 2003. Parkin-deficient mice exhibit nigrostriatal deficits but not loss of dopaminergic neurons. J Biol Chem 278: 43628-43635.

Goldman SJ, Taylor R, Zhang Y, Jin S. 2010. Autophagy and the degradation of mitochondria. Mitochondrion 10: 309-315.

Greene JC, Whitworth AJ, Kuo I, Andrews LA, Feany MB, Pallanck LJ. 2003. Mitochondrial pathology and apoptotic muscle degeneration in Drosophila parkin mutants. Proc Natl Acad Sci 100: 4078-4083.

Greene JC, Whitworth AJ, Andrews LA, Parker TJ, Pallanck LJ. 2005. Genetic and genomic studies of Drosophila parkin mutants implicate oxidative stress and innate immune responses in pathogenesis. Hum Mol Genet 14: 799-811.

Grünewald A, Voges L, Rakovic A, Kasten M, Vandebona H, Hemmelmann C, Lohmann K, Orolicki S, Ramirez A, Schapira AH, et al. 2010. Mutant Parkin impairs mitochondrial function and morphology in human fibroblasts. PLoS ONE 5: e12962.

Guo M. 2010. What have we learned from Drosophila models of Parkinson's disease? Prog Brain Res 184: 3-16.

Guo X, Macleod GT, Wellington A, Hu F, Panchumarthi S, Schoenfield M, Marin L, Charlton MP, Atwood HL, Zinsmaier KE. 2005. The GTPase dMiro is required for axonal transport of mitochondria to Drosophila synapses. Neuron 47: 379-393.

Hao LY, Giasson BI, Bonini NM. 2010. DJ-1 is critical for mitochondrial function and rescues PINK1 loss of function. Proc Natl Acad Sci 107: 9747-9752.

Hardy J, Lewis P, Revesz T, Lees A, Paisan-Ruiz C. 2009. The genetics of Parkinson's syndromes: A critical review. Curr Opin Genet Dev 19: 254-265.

Hay BA, Guo M. 2006. Caspase-dependent cell death in Drosophila. Annu Rev Cell Dev Biol 22: 623-650.

Hay BA, Huh JR, Guo M. 2004. The genetics of cell death: Approaches, insights and opportunities in Drosophila. Nat Rev Genet 5: 911-922.

Hoepken HH, Gispert S, Morales B, Wingerter O, Del Turco D, Mulsch A, Nussbaum RL, Muller K, Drose S, Brandt U, et al. 2007. Mitochondrial dysfunction, peroxidation damage and changes in glutathione metabolism in PARK6. Neurobiol Dis 25: 401-411.

Hyde BB, Twig G, Shirihai OS. 2010. Organellar vs cellular control of mitochondrial dynamics. Semin Cell Dev Biol 21: $575-581$.

Ibanez P, Lesage S, Lohmann E, Thobois S, De Michele G, Borg M, Agid Y, Durr A, Brice A. 2006. Mutational analysis of the PINK1 gene in early-onset parkinsonism in Europe and North Africa. Brain 129: 686-694.

Imai Y, Kanao T, Sawada T, Kobayashi Y, Moriwaki Y, Ishida Y, Takeda K, Ichijo H, Lu B, Takahashi R. 2010. The loss of PGAM5 suppresses the mitochondrial degeneration caused by inactivation of PINK1 in Drosophila. PLoS Genet 6: e1001229.

Itier JM, Ibanez P, Mena MA, Abbas N, Cohen-Salmon C, Bohme GA, Laville M, Pratt J, Corti O, Pradier L, et al. 2003. Parkin gene inactivation alters behaviour and 
M. Guo

dopamine neurotransmission in the mouse. Hum Mol Genet 12: 2277-2291.

Jin SM, Lazarou M, Wang C, Kane LA, Narendra DP, Youle RJ. 2010. Mitochondrial membrane potential regulates PINK1 import and proteolytic destabilization by PARL. J Cell Biol 191: 933-942.

Jones JM, Datta P, Srinivasula SM, Ji W, Gupta S, Zhang Z, Davies E, Hajnoczky G, Saunders TL, Van Keuren ML, et al. 2003. Loss of Omi mitochondrial protease activity causes the neuromuscular disorder of mnd2 mutant mice. Nature 425: 721-727.

Junn E, Jang WH, Zhao X, Jeong BS, Mouradian MM. 2009. Mitochondrial localization of DJ-1 leads to enhanced neuroprotection. J Neurosci Res 87: 123-129.

Kim Y, Park J, Kim S, Song S, Kwon SK, Lee SH, Kitada T, Kim JM, Chung J. 2008. PINK1 controls mitochondrial localization of Parkin through direct phosphorylation. Biochem Biophys Res Commun 377: 975-980.

Kitada T, Asakawa S, Hattori N, Matsumine H, Yamamura Y, Minoshima S, Yokochi M, Mizuno Y, Shimizu N. 1998. Mutations in the parkin gene cause autosomal recessive juvenile parkinsonism. Nature 392: 605-608.

Kitada T, Tong Y, Gautier CA, Shen J. 2009. Absence of nigral degeneration in aged parkin/DJ-1/PINK1 triple knockout mice. J Neurochem 111: 696-702.

Koh H, Kim H, Kim MJ, Park J, Lee HJ, Chung J. 2012. Silent information regulator 2 (Sir2) and Forkhead box O (FOXO) complement mitochondrial dysfunction and dopaminergic neuron loss in Drosophila Pten-induced kinase 1 (PINK1) null mutant. J Biol Chem 278: 12750 12758.

Langston JW, Ballard P, Tetrud JW, Irwin I. 1983. Chronic Parkinsonism in humans due to a product of meperidine-analog synthesis. Science 219: 979-980.

Lessing D, Bonini NM. 2009. Maintaining the brain: Insight into human neurodegeneration from Drosophila melanogaster mutants. Nat Rev Genet 10: 359-370.

Lev N, Ickowicz D, Melamed E, Offen D. 2008. Oxidative insults induce DJ-1 upregulation and redistribution: Implications for neuroprotection. Neurotoxicology 29: $397-$ 405.

Linazasoro G. 2004. Recent failures of new potential symptomatic treatments for Parkinson's disease: Causes and solutions. Mov Disord 19: 743-754.

Liu S, Lu B. 2010. Reduction of protein translation and activation of autophagy protect against PINK1 pathogenesis in Drosophila melanogaster. PLoS Genet 6: e1001237.

Liu W, Acin-Perez R, Geghman KD, Manfredi G, Lu B, Li C. 2011. Pink1 regulates the oxidative phosphorylation machinery via mitochondrial fission. Proc Natl Acad Sci 108: 12920-12924.

Liu S, Sawada T, Lee S, Yu W, Silverio G, Alapatt P, Millan I, Shen A, Saxton W, Kanao T, et al. 2012. Parkinson's disease-associated kinase PINK1 regulates Miro protein level and axonal transport of mitochondria. PLoS Genet 8: e1002537.

Lu B, Vogel H. 2009. Drosophila models of neurodegenerative diseases. Annu Rev Pathol 4: 315-342.

Lutz AK, Exner N, Fett ME, Schlehe JS, Kloos K, Lammermann K, Brunner B, Kurz-Drexler A, Vogel F, Reichert
AS, et al. 2009. Loss of parkin or PINK1 function increases Drp1-dependent mitochondrial fragmentation. J Biol Chem 284: 22938-22951.

Martin I, Dawson VL, Dawson TM. 2011. Recent advances in the genetics of Parkinson's disease. Annu Rev Genomics Hum Genet 12: 301-325.

Martins LM, Morrison A, Klupsch K, Fedele V, Moisoi N, Teismann P, Abuin A, Grau E, Geppert M, Livi GP, et al. 2004. Neuroprotective role of the Reaper-related serine protease $\mathrm{HtrA} 2 / \mathrm{Omi}$ revealed by targeted deletion in mice. Mol Cell Biol 24: 9848-9862.

McQuibban GA, Lee JR, Zheng L, Juusola M, Freeman M. 2006. Normal mitochondrial dynamics requires rhomboid-7 and affects Drosophila lifespan and neuronal function. Curr Biol 16: 982-989.

Meissner C, Lorenz H, Weihofen A, Selkoe DJ, Lemberg MK. 2011a. The mitochondrial intramembrane protease PARL cleaves human Pink1 to regulate Pink1 trafficking. J Neurochem 117: 856-867.

Meissner WG, Frasier M, Gasser T, Goetz CG, Lozano A, Piccini P, Obeso JA, Rascol O, Schapira A, Voon V, et al. 2011b. Priorities in Parkinson's disease research. Nat Rev Drug Discov 10: 377-393.

Menzies FM, Yenisetti SC, Min KT. 2005. Roles of Drosophila DJ-1 in survival of dopaminergic neurons and oxidative stress. Curr Biol 15: 1578-1582.

Meulener M, Whitworth AJ, Armstrong-Gold CE, Rizzu P, Heutink P, Wes PD, Pallanck LJ, Bonini NM. 2005. Drosophila DJ-1 mutants are selectively sensitive to environmental toxins associated with Parkinson's disease. Curr Biol 15: 1572-1577.

Meulener MC, Xu K, Thomson L, Ischiropoulos H, Bonini NM. 2006. Mutational analysis of DJ-1 in Drosophila implicates functional inactivation by oxidative damage and aging. Proc Natl Acad Sci 103: 12517-12522.

Morais VA, Verstreken P, Roethig A, Smet J, Snellinx A, Vanbrabant M, Haddad D, Frezza C, Mandemakers W, VogtWeisenhorn D, et al. 2009. Parkinson's disease mutations in PINK1 result in decreased Complex I activity and deficient synaptic function. EMBO Mol Med 1: 99-111.

Muftuoglu M, Elibol B, Dalmizrak O, Ercan A, Kulaksiz G, Ogus H, Dalkara T, Ozer N. 2004. Mitochondrial complex I and IV activities in leukocytes from patients with parkin mutations. Mov Disord 19: 544-548.

Mukhopadhyay D, Riezman H. 2007. Proteasome-independent functions of ubiquitin in endocytosis and signaling. Science 315: 201-205.

Narendra D, Tanaka A, Suen DF, Youle RJ. 2008. Parkin is recruited selectively to impaired mitochondria and promotes their autophagy. J Cell Biol 183: 795-803.

Narendra D, Tanaka A, Suen DF, Youle RJ. 2009. Parkininduced mitophagy in the pathogenesis of Parkinson disease. Autophagy 5: 706-708.

Narendra D, Kane LA, Hauser DN, Fearnley IM, Youle RJ. 2010a. p62/SQSTM1 is required for Parkin-induced mitochondrial clustering but not mitophagy; VDAC1 is dispensable for both. Autophagy 6: 1090-1106.

Narendra DP, Jin SM, Tanaka A, Suen DF, Gautier CA, Shen J, Cookson MR, Youle RJ. 2010b. PINK1 is selectively stabilized on impaired mitochondria to activate Parkin. PLoS Biol 8: e1000298. 
Nassel DR, Elekes K. 1992. Aminergic neurons in the brain of blowflies and Drosophila: Dopamine- and tyrosine hydroxylase-immunoreactive neurons and their relationship with putative histaminergic neurons. Cell Tissue Res 267: 147-167.

Ni JQ, Zhou R, Czech B, Liu LP, Holderbaum L, Yang-Zhou D, Shim HS, Tao R, Handler D, Karpowicz P, et al. 2011. A genome-scale shRNA resource for transgenic RNAi in Drosophila. Nat Methods 8: 405-407.

Ooe H, Taira T, Iguchi-Ariga SM, Ariga H. 2005. Induction of reactive oxygen species by bisphenol $\mathrm{A}$ and abrogation of bisphenol A-induced cell injury by DJ-1. Toxicol Sci 88: 114-126.

Paisan-Ruiz C, Jain S, Evans EW, Gilks WP, Simon J, van der Brug M, Lopez de Munain A, Aparicio S, Gil AM, Khan $\mathrm{N}$, et al. 2004. Cloning of the gene containing mutations that cause PARK8-linked Parkinson's disease. Neuron 44: 595-600.

Palacino JJ, Sagi D, Goldberg MS, Krauss S, Motz C, Wacker M, Klose J, Shen J. 2004. Mitochondrial dysfunction and oxidative damage in parkin-deficient mice. J Biol Chem 279: 18614-18622.

Pandey UB, Nichols CD. 2011. Human disease models in Drosophila melanogaster and the role of the fly in therapeutic drug discovery. Pharmacol Rev 63: 411-436.

Park J, Lee SB, Lee S, Kim Y, Song S, Kim S, Bae E, Kim J, Shong M, Kim JM, et al. 2006. Mitochondrial dysfunction in Drosophila PINK1 mutants is complemented by parkin. Nature 441: 1157-1161.

Park J, Lee G, Chung J. 2009. The PINK1-Parkin pathway is involved in the regulation of mitochondrial remodeling process. Biochem Biophys Res Commun 378: 518-523.

Perez FA, Palmiter RD. 2005. Parkin-deficient mice are not a robust model of parkinsonism. Proc Natl Acad Sci 102: 2174-2179.

Pesah Y, Pham T, Burgess H, Middlebrooks B, Verstreken P, Zhou Y, Harding M, Bellen H, Mardon G. 2004. Drosophila parkin mutants have decreased mass and cell size and increased sensitivity to oxygen radical stress. Development 131: 2183-2194.

Plun-Favreau H, Klupsch K, Moisoi N, Gandhi S, Kjaer S, Frith D, Harvey K, Deas E, Harvey RJ, McDonald N, et al. 2007. The mitochondrial protease HtrA2 is regulated by Parkinson's disease-associated kinase PINK1. Nat Cell Biol 9: 1243-1252.

Polymeropoulos MH, Lavedan C, Leroy E, Ide SE, Dehejia A, Dutra A, Pike B, Root H, Rubenstein J, Boyer R, et al. 1997. Mutation in the $\alpha$-synuclein gene identified in families with Parkinson's disease. Science 276: 2045-2047.

Poole AC, Thomas RE, Andrews LA, McBride HM, Whitworth AJ, Pallanck LJ. 2008. The PINK1/Parkin pathway regulates mitochondrial morphology. Proc Natl Acad Sci 105: $1638-1643$.

Poole AC, Thomas RE, Yu S, Vincow ES, Pallanck L. 2010. The mitochondrial fusion-promoting factor Mitofusin is a substrate of the PINK1/Parkin pathway. PLoS ONE 5: e10054.

Rakovic A, Grunewald A, Kottwitz J, Bruggemann N, Pramstaller PP, Lohmann K, Klein C. 2011. Mutations in PINK1 and Parkin impair ubiquitination of Mitofusins in human fibroblasts. PLoS ONE 6: e16746.
Ramirez A, Heimbach A, Grundemann J, Stiller B, Hampshire D, Cid LP, Goebel I, Mubaidin AF, Wriekat AL, Roeper J, et al. 2006. Hereditary parkinsonism with dementia is caused by mutations in ATP13A2, encoding a lysosomal type 5 P-type ATPase. Nat Genet 38: 1184-1191.

Rathke-Hartlieb S, Schlomann U, Heimann P, Meisler MH, Jockusch H, Bartsch JW. 2002. Progressive loss of striatal neurons causes motor dysfunction in MND2 mutant mice and is not prevented by Bcl-2. Exp Neurol 175: 87-97.

Riparbelli MG, Gallaini G. 2006. The Drosophila parkin homologue is required for normal mitochondrial dynamics during spermiogenesis. Dev Biol 303: 108-120.

Rong YS, Golic KG. 2000. Gene targeting by homologous recombination in Drosophila. Science 288: 2013-2018.

Rorth P. 1996. A modular misexpression screen in Drosophila detecting tissue-specific phenotypes. Proc Natl Acad Sci 124: $12418-12422$

Ross OA, Soto AI, Vilarino-Guell C, Heckman MG, Diehl NN, Hulihan MM, Aasly JO, Sando S, Gibson JM, Lynch T, et al. 2008. Genetic variation of Omi/HtrA2 and Parkinson's disease. Parkinsonism Relat Disord 14: 539-543.

Rubin GM. 2000. Biological annotation of the Drosophila genome sequence. Novartis Found Symp 229: 79-82.

Saini N, Georgiev O, Schaffner W. 2011. The parkin mutant phenotype in the fly is largely rescued by metal-responsive transcription factor (MTF-1). Mol Cell Biol 31: 2151-2161.

Sandebring A, Thomas KJ, Beilina A, van der Brug M, Cleland MM, Ahmad R, Miller DW, Zambrano I, Cowburn RF, Behbahani H, et al. 2009. Mitochondrial alterations in PINK1 deficient cells are influenced by calcineurindependent dephosphorylation of dynamin-related protein 1. PLoS ONE 4: e5701.

Satake W, Nakabayashi Y, Mizuta I, Hirota Y, Ito C, Kubo M, Kawaguchi T, Tsunoda T, Watanabe M, Takeda A, et al. 2009. Genome-wide association study identifies common variants at four loci as genetic risk factors for Parkinson's disease. Nat Genet 41: 1303-1307.

Schmidt S, Linnartz B, Mendritzki S, Sczepan T, Lubbert M, Stichel CC, Lubbert H. 2011. Genetic mouse models for Parkinson's disease display severe pathology in glial cell mitochondria. Hum Mol Genet 20: 1197-1211.

Schneider SA, Paisan-Ruiz C, Quinn NP, Lees AJ, Houlden H, Hardy J, Bhatia KP. 2010. ATP13A2 mutations (PARK9) cause neurodegeneration with brain iron accumulation. Mov Disord 25: 979-984.

Seibler P, Graziotto J, Jeong H, Simunovic F, Klein C, Krainc D. 2011. Mitochondrial Parkin recruitment is impaired in neurons derived from mutant PINK1 induced pluripotent stem cells. J Neurosci 31: 5970-5976.

Sha D, Chin LS, Li L. 2010. Phosphorylation of Parkin by Parkinson disease-linked kinase PINK1 activates Parkin E3 ligase function and NF-кB signaling. Hum Mol Genet 19: $352-363$

Sherer TB, Betarbet R, Testa CM, Seo BB, Richardson JR, Kim JH, Miller GW, Yagi T, Matsuno-Yagi A, Greenamyre JT. 2003. Mechanism of toxicity in rotenone models of Parkinson's disease. J Neurosci 23: 10756-10764. 
M. Guo

Shi G, Lee JR, Grimes DA, Racacho L, Ye D, Yang H, Ross OA, Farrer M, McQuibban GA, Bulman DE. 2011. Functional alteration of PARL contributes to mitochondrial dysregulation in Parkinson's disease. Hum Mol Genet 20: 1966-1974.

Shim JH, Yoon SH, Kim KH, Han JY, Ha JY, Hyun DH, Paek SH, Kang UJ, Zhuang X, Son JH. 2011. The antioxidant Trolox helps recovery from the familial Parkinson's disease-specific mitochondrial deficits caused by PINK1and DJ-1-deficiency in dopaminergic neuronal cells. Mitochondrion 11: 707-715.

Shin JH, Ko HS, Kang H, Lee Y, Lee YI, Pletinkova O, Troconso JC, Dawson VL, Dawson TM. 2011. PARIS (ZNF746) repression of PGC- $1 \alpha$ contributes to neurodegeneration in Parkinson's disease. Cell 144: 689-702.

Shulman JM, De Jager PL, Feany MB. 2011. Parkinson's disease: Genetics and pathogenesis. Annu Rev Pathol 6: $193-222$.

Simon-Sanchez J, Singleton AB. 2008. Sequencing analysis of OMI/HTRA2 shows previously reported pathogenic mutations in neurologically normal controls. Hum Mol Genet 17: 1988-1993.

Simon-Sanchez J, Schulte C, Bras JM, Sharma M, Gibbs JR, Berg D, Paisan-Ruiz C, Lichtner P, Scholz SW, Hernandez DG, et al. 2009. Genome-wide association study reveals genetic risk underlying Parkinson's disease. Nat Genet 41: $1308-1312$.

Simuni T, Sethi K. 2008. Nonmotor manifestations of Parkinson's disease. Ann Neurol 64: S65-S80.

Singleton AB, Farrer M, Johnson J, Singleton A, Hague S, Kachergus J, Hulihan M, Peuralinna T, Dutra A, Nussbaum R, et al. 2003. $\alpha$-Synuclein locus triplication causes Parkinson's disease. Science 302: 841.

Stichel CC, Zhu XR, Bader V, Linnartz B, Schmidt S, Lubbert H. 2007. Mono- and double-mutant mouse models of Parkinson's disease display severe mitochondrial damage. Hum Mol Genet 16: 2377-2393.

St Johnston D. 2002. The art and design of genetic screens: Drosophila melanogaster. Nat Rev Genet 3: 176-188.

Stowers RS, Megeath LJ, Gorska-Andrzejak J, Meinertzhagen IA, Schwarz TL. 2002. Axonal transport of mitochondria to synapses depends on Milton, a novel Drosophile protein. Neuron 36: 1063-1077.

Strauss KM, Martins LM, Plun-Favreau H, Marx FP, Kautzmann S, Berg D, Gasser T, Wszolek Z, Muller T, Bornemann A, et al. 2005. Loss of function mutations in the gene encoding Omi/HtrA2 in Parkinson's disease. Hum Mol Genet 14: 2099-2111.

Tain LS, Mortiboys H, Tao RN, Ziviani E, Bandmann O, Whitworth AJ. 2009. Rapamycin activation of 4E-BP prevents parkinsonian dopaminergic neuron loss. $\mathrm{Nat} \mathrm{Neu-}$ rosci 12: 1129-1135.

Tanaka A, Cleland MM, Xu S, Narendra DP, Suen DF, Karbowski M, Youle RJ. 2011. Proteasome and p97 mediate mitophagy and degradation of mitofusins induced by Parkin. J Cell Biol 191: 1367-1380.

Thibault ST, Singer MA, Miyazaki WY, Milash B, Dompe NA, Singh CM, Buchholz R, Demsky M, Fawcett R, Francis-Lang HL, et al. 2004. A complementary transposon tool kit for Drosophila melanogaster using $P$ and piggyBac. Nat Genet 36: 283-287.
Trinh K, Moore K, Wes PD, Muchowski PJ, Dey J, Andrews L, Pallanck LJ. 2008. Induction of the phase II detoxification pathway suppresses neuron loss in Drosophila models of Parkinson's disease. J Neurosci 28: 465-472.

Twig G, Shirihai OS. 2011. The interplay between mitochondrial dynamics and mitophagy. Antioxid Redox Signal 14: 1939-1951.

Twig G, Elorza A, Molina AJ, Mohamed H, Wikstrom JD, Walzer G, Stiles L, Haigh SE, Katz S, Las G, et al. 2008. Fission and selective fusion govern mitochondrial segregation and elimination by autophagy. $E M B O J$ 27: 433-446.

Valente EM, Abou-Sleiman PM, Caputo V, Muqit MM, Harvey K, Gispert S, Ali Z, Del Turco D, Bentivoglio AR, Healy DG, et al. 2004. Hereditary early-onset Parkinson's disease caused by mutations in PINK1. Science 304: $1158-1160$.

Vande Walle L, Lamkanfi M, Vandenabeele P. 2008. The mitochondrial serine protease HtrA2/Omi: An overview. Cell Death Differ 15: 453-460.

Venken KJ, Bellen HJ. 2005. Emerging technologies for gene manipulation in Drosophila melanogaster. Nat Rev Genet 6: $167-178$.

Venken KJ, Bellen HJ. 2007. Transgenesis upgrades for Drosophila melanogaster. Development 134: 3571-3584.

Vilain S, Esposito G, Haddad D, Schaap O, Dobreva MP, Vos M, Van Meensel S, Morais VA, De Strooper B, Verstreken P. 2012. The yeast complex I equivalent NADH dehydrogenase rescues pink1 mutants. PLoS Genet 8: e1002456.

Vilarino-Guell C, Wider C, Ross OA, Dachsel JC, Kachergus JM, Lincoln SJ, Soto-Ortolaza AI, Cobb SA, Wilhoite GJ, Bacon JA, et al. 2011. VPS35 mutations in Parkinson disease. Am J Hum Genet 89: 162-167.

Vives-Bauza C, Zhou C, Huang Y, Cui M, de Vries RL, Kim J, May J, Tocilescu MA, Liu W, Ko HS, et al. 2010. PINK1dependent recruitment of Parkin to mitochondria in mitophagy. Proc Natl Acad Sci 107: 378-383.

Von Coelln R, Thomas B, Savitt JM, Lim KL, Sasaki M, Hess EJ, Dawson VL, Dawson TM. 2004. Loss of locus coeruleus neurons and reduced startle in parkin null mice. Proc Natl Acad Sci 101: 10744-10749.

Wang H, Song P, Du L, Tian W, Yue W, Liu M, Li D, Wang B, Zhu Y, Cao C, et al. 2011a. Parkin ubiquitinates Drpl for proteasome-dependent degradation: Implication of dysregulated mitochondrial dynamics in Parkinson disease. J Biol Chem 286: 11649-11658.

Wang X, Winter D, Ashrafi G, Schlehe J, Wong YL, Selkoe D, Rice S, Steen J, LaVoie MJ, Schwarz TL. 2011b. PINK1 and Parkin target Miro for phosphorylation and degradation to arrest mitochondrial motility. Cell 147: $893-$ 906.

Weihofen A, Thomas KJ, Ostaszewski BL, Cookson MR, Selkoe DJ. 2009. Pink1 forms a multiprotein complex with Miro and Milton, linking Pink1 function to mitochondrial trafficking. Biochemistry 48: 2045-2052.

Wesolowska N, Rong YS. 2010. The past, present and future of gene targeting in Drosophila. Fly (Austin) 4: 53-59.

West AB, Dawson VL, Dawson TM. 2007. The role of Parkin in Parkinson's disease. In Parkinson's disease: Genetics and pathogenesis (ed. Dawson TM), pp. 199-218. Informa Healthcare, New York. 
Whitworth AJ. 2011. Drosophila models of Parkinson's disease. Adv Genet 73: 1-50.

Whitworth AJ, Theodore DA, Greene JC, Benes H, Wes PD, Pallanck LJ. 2005. Increased glutathione S-transferase activity rescues dopaminergic neuron loss in a Drosophila model of Parkinson's disease. Proc Natl Acad Sci 102: 8024-8029.

Whitworth AJ, Lee JR, Ho VM, Flick R, Chowdhury R, McQuibban GA. 2008. Rhomboid-7 and HtrA2/Omi act in a common pathway with the Parkinson's disease factors Pink1 and Parkin. Dis Model Mech 1: 168-174.

Wilson MA. 2011. The role of cysteine oxidation in DJ-1 function and dysfunction. Antioxid Redox Signal 15: $111-122$.

Wood-Kaczmar A, Gandhi S, Yao Z, Abramov AY, Miljan EA, Keen G, Stanyer L, Hargreaves I, Klupsch K, Deas E, et al. 2008. PINK1 is necessary for long term survival and mitochondrial function in human dopaminergic neurons. PLoS ONE 3: e2455.

Xiong H, Wang D, Chen L, Choo YS, Ma H, Tang C, Xia K, Jiang W, Ronai Z, Zhuang X, et al. 2009. Parkin, PINK1, and DJ-1 form a ubiquitin E3 ligase complex promoting unfolded protein degradation. JClin Invest 119: 650-660.

Yang Y, Gehrke S, Imai Y, Huang Z, Ouyang Y, Wang JW, Yang L, Beal MF, Vogel H, Lu B. 2006. Mitochondrial pathology and muscle and dopaminergic neuron degeneration caused by inactivation of Drosophila Pink1 is rescued by Parkin. Proc Natl Acad Sci 103: 10793-10798.

Yang Y, Ouyang Y, Yang L, Beal MF, McQuibban A, Vogel H, Lu B. 2008. Pink1 regulates mitochondrial dynamics through interaction with the fission/fusion machinery. Proc Natl Acad Sci 105: 7070-7075.

Yoshida T, Mizuta T, Shimizu S. 2010. Neurodegeneration in mnd2 mutant mice is not prevented by parkin transgene. Biochem Biophys Res Commun 402: 676-679.
Yoshii SR, Kishi C, Ishihara N, Mizushima N. 2011. Parkin mediates proteasome-dependent protein degradation and rupture of the outer mitochondrial membrane. $J$ Biol Chem 286: 19630-19640.

Yu W, Sun Y, Guo S, Lu B. 2011. The PINK1/Parkin pathway regulates mitochondrial dynamics and function in mammalian hippocampal and dopaminergic neurons. Hum Mol Genet 20: 3227-3240.

Yun J, Cao JH, Dodson MW, Clark IE, Kapahi P, Chowdhury RB, Guo M. 2008. Loss-of-function analysis suggests that Omi/HtrA2 is not an essential component of the PINK1/PARKIN pathway in vivo. J Neurosci 28: $14500-$ 14510.

Zhou C, Huang Y, Shao Y, May J, Prou D, Perier C, Dauer W, Schon EA, Przedborski S. 2008. The kinase domain of mitochondrial PINK1 faces the cytoplasm. Proc Natl Acad Sci 105: 12022-12027.

Zimprich A, Biskup S, Leitner P, Lichtner P, Farrer M, Lincoln S, Kachergus J, Hulihan M, Uitti RJ, Calne DB, et al. 2004. Mutations in LRRK2 cause autosomal-dominant parkinsonism with pleomorphic pathology. Neuron 44: 601-607.

Zimprich A, Benet-Pages A, Struhal W, Graf E, Eck SH, Offman MN, Haubenberger D, Spielberger S, Schulte EC, Lichtner P, et al. 2011. A mutation in VPS35, encoding a subunit of the retromer complex, causes late-onset Parkinson disease. Am J Hum Genet 89: 168-175.

Ziviani E, Tao RN, Whitworth AJ. 2010. Drosophila parkin requires PINK1 for mitochondrial translocation and ubiquitinates mitofusin. Proc Natl Acad Sci 107: 5018 5023.

Zoghbi HY, Warren ST. 2010. Neurogenetics: Advancing the "next-generation" of brain research. Neuron 68: $165-173$. 


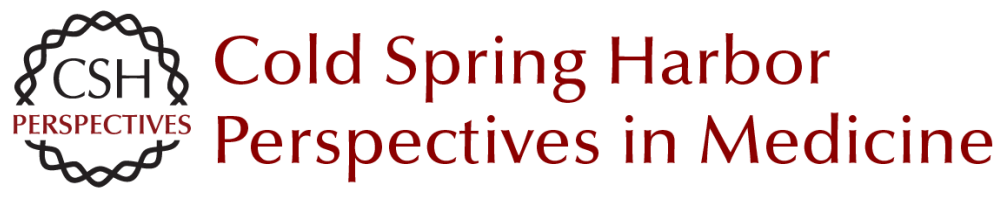

\section{Drosophila as a Model to Study Mitochondrial Dysfunction in Parkinson's Disease}

Ming Guo

Cold Spring Harb Perspect Med 2012; doi: 10.1101/cshperspect.a009944 originally published online September 28, 2012

\section{Subject Collection Parkinson's Disease}

Functional Neuroanatomy of the Basal Ganglia José L. Lanciego, Natasha Luquin and José A. Obeso

Animal Models of Parkinson's Disease: Vertebrate Genetics Yunjong Lee, Valina L. Dawson and Ted M. Dawson

Innate Inflammation in Parkinson's Disease V. Hugh Perry

Parkinson's Disease and Parkinsonism:

Neuropathology

Dennis W. Dickson

Physiological Phenotype and Vulnerability in Parkinson's Disease

$D$. James Surmeier, Jaime N. Guzman, Javier Sanchez, et al.

Clinical Approach to Parkinson's Disease:

Features, Diagnosis, and Principles of

Management João Massano and Kailash P. Bhatia

The Role of Autophagy in Parkinson's Disease Melinda A. Lynch-Day, Kai Mao, Ke Wang, et al.

Disruption of Protein Quality Control in

Parkinson's Disease

Casey Cook, Caroline Stetler and Leonard Petrucelli

\section{Drosophila as a Model to Study Mitochondrial Dysfunction in Parkinson's Disease Ming Guo}

Parkinsonism Due to Mutations in PINK1, Parkin, and DJ-1 and Oxidative Stress and Mitochondrial Pathways Mark R. Cookson

\section{Programmed Cell Death in Parkinson's Disease} Katerina Venderova and David S. Park

Genomics and Bioinformatics of Parkinson's Disease

Sonja W. Scholz, Tim Mhyre, Habtom Ressom, et al.

Motor Control Abnormalities in Parkinson's

Disease

Pietro Mazzoni, Britne Shabbott and Juan Camilo Cortés

Parkinson's Disease: Gene Therapies Philippe G. Coune, Bernard L. Schneider and Patrick Aebischer

Functional Neuroimaging in Parkinson's Disease Martin Niethammer, Andrew Feigin and David Eidelberg

Leucine-Rich Repeat Kinase 2 for Beginners: Six Key Questions Lauren R. Kett and William T. Dauer

For additional articles in this collection, see http://perspectivesinmedicine.cshlp.org/cgi/collection/ 